\title{
A Novel Description of Increased Urinary Orotic Acid Excretion in Pediatric Trauma
}

\author{
Thipwimol Tim-Aroon ${ }^{\mathrm{a}}$, Ingrid M Anderson ${ }^{\mathrm{b}}$, Steven Shein ${ }^{\mathrm{b}}$, \\ Jirair K Bedoyan a, c, d
}

\begin{abstract}
The diagnostic utility of orotic aciduria for suspected inborn errors of metabolism is well established. Orotic aciduria has been reported in traumatized adults, but not in children. A 2-year-old hyperammonemic girl with cardiac arrest and abdominal compartment syndrome secondary to non-accidental trauma with significant orotic aciduria is presented. To our knowledge, this is the first report highlighting the association of transiently elevated urinary orotic acid and mild uricosuria with severe trauma in children. Further investigations into the clinical use of orotic acid excretion as a biomarker of the catabolic state of pediatric trauma or other critical illness are warranted.
\end{abstract}

Keywords: Orotic aciduria; Uricosuria; Trauma; Urea cycle disorders; Abdominal compartment syndrome; Inborn error of metabolism

\section{Introduction}

Elevated amounts of specific metabolites in bodily fluids such as urine, blood or CSF provide important clues for the diagnosis of an underlying inborn error of metabolism (IEM) or syndrome. Orotic acid (OA) is one such metabolite and its link to several metabolic pathways is shown in Figure 1. A block distal to the formation of mitochondrial carbamoyl

\footnotetext{
Manuscript accepted for publication February 26, 2014

${ }^{\mathrm{a} C e n t e r}$ for Human Genetics, University Hospitals Case Medical Center, Cleveland, $\mathrm{OH}$, USA

${ }^{\mathrm{b}}$ Department of Pediatrics-Pediatric Critical Care, UH Rainbow Babies and Children's Hospital, Cleveland, OH, USA

${ }^{\mathrm{c}}$ Center for Inherited Disorders of Energy Metabolism (CIDEM),

University Hospitals Case Medical Center, Cleveland, OH, USA

${ }^{\mathrm{d} C}$ Corresponding author: Jirair K Bedoyan, Center for Human

Genetics, 1500 Lakeside, University Hospitals Case Medical Center,

11100 Euclid Avenue, Cleveland, OH 44106, USA.

Email: jirair.bedoyan@uhhospitals.org

doi: http://dx.doi.org/10.14740/jem209w
}

phosphate $(\mathrm{CP})$ in the urea cycle results in excessive excretion of OA in the urine $[1,2]$. In ornithine transcarbamylase (OTC) deficiency, the most common urea cycle disorder [3], elevated mitochondrial CP is shunted into the cytosolic pathway for the de novo synthesis of pyrimidines (Fig. 1) [1, 2]. Elevated levels of urine OA can also be due to disorders of pyrimidine and purine metabolism (for example, uridine monophosphate synthase deficiency-hereditary orotic aciduria $[4,5]$ and purine nucleoside phosphorylase deficiency $[5,6])$, lysinuric protein intolerance [7], syndromes such as Rett [8], Reye [9], and Lesch-Nyhan [10], certain cases of pervasive developmental delay [11], and drugs (for example, allopurinol and 6-azauridine [12]) (Table 1). Orotic aciduria has been reported in traumatized adults as a marker of catabolism [13], but we are unaware of any prior reports of orotic aciduria in traumatized children.

\section{Case Report}

A previously healthy 2-year-old girl presented to a local emergency department (ED) with drowsiness, burns on her legs and multiple episodes of brownish emesis. In the ED, she developed seizures and had a cardiac arrest. Treatments prior to return of spontaneous circulation included chest compressions, two doses of epinephrine, bicarbonate, PRBC infusion and endotracheal intubation. Upon transfer to our facility, she was comatose. Initial evaluation included a head CT without intracranial hemorrhage and an abdominal CT without pneumoperitoneum. She was mechanically ventilated, fluid resuscitated, treated with broad spectrum antimicrobials and kept hypothermic $\left(32-34^{\circ} \mathrm{C}\right)$. Over the subsequent 36 hours, she developed abdominal compartment syndrome associated with increasing mechanical ventilator settings, escalating vasoactive infusions, Klebsiella sepsis and anuria. Laboratory workup during this time showed elevated BUN ( $37 \mathrm{mg} / \mathrm{dL}$; reference interval (RI): 6 - $23 \mathrm{mg} / \mathrm{dL}$ ), creatinine $(2.31 \mathrm{mg} / \mathrm{dL}$; RI $0.30-1.10 \mathrm{mg} / \mathrm{dL}$ ), liver enzymes (ALT $935 \mathrm{U} / \mathrm{L} ; \mathrm{RI} 7$ - $54 \mathrm{U} / \mathrm{L}$ and AST 1,962 U/L; RI 10 - $60 \mathrm{U} / \mathrm{L}$ ), creatine kinase (36,570 U/L; RI 0 - $240 \mathrm{U} / \mathrm{L})$, plasma lactate (9.30 mM; RI $0.60-2.40 \mathrm{mM}$ ) and ammonia (93 mM; RI $\leq 32$ ). Further metabolic workup showed that most plasma 


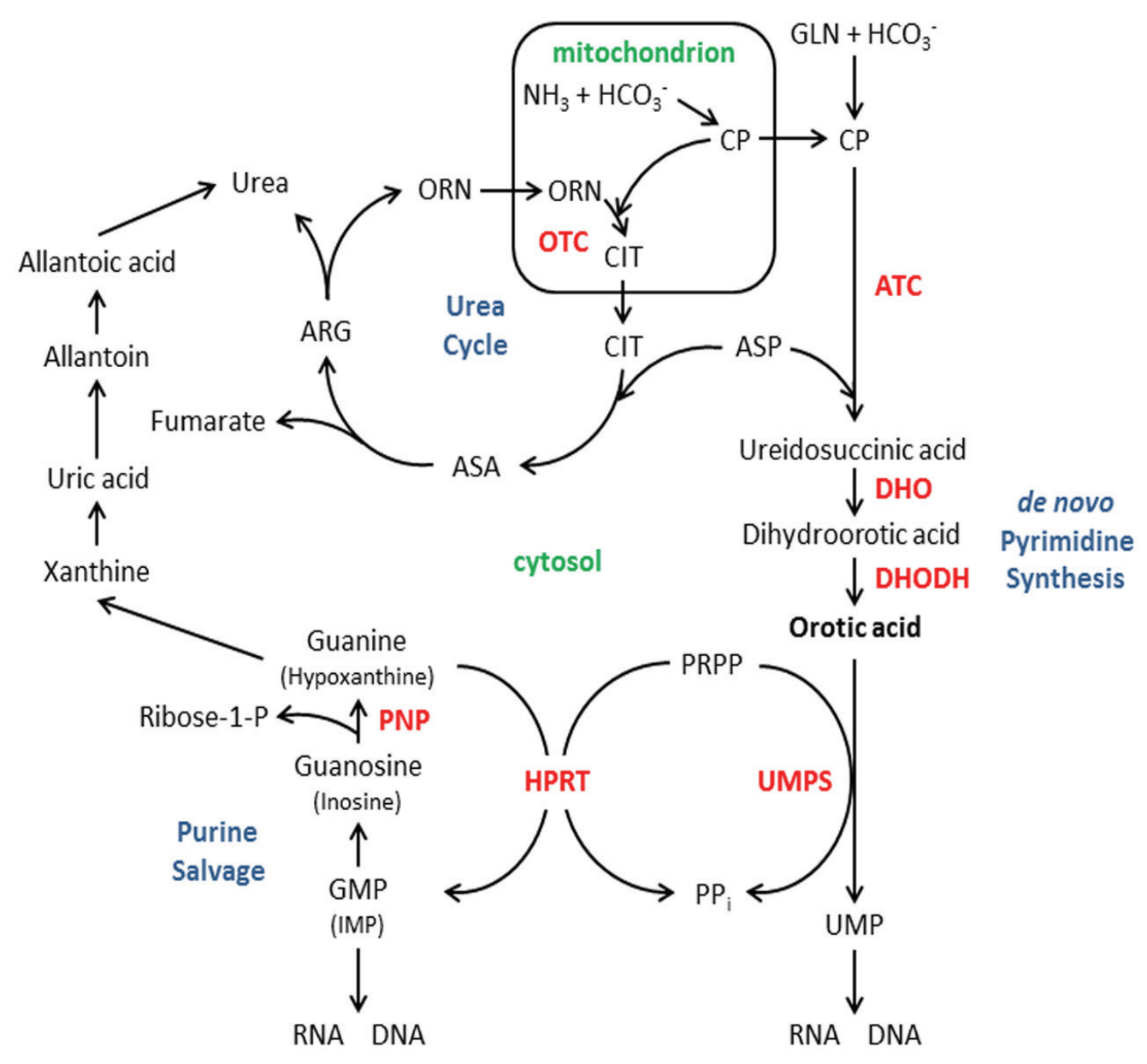

Figure 1. Orotic acid in relation to several metabolic pathways: the urea cycle, the de novo pyrimidine synthesis pathway and the purine salvage pathway. Enzymes shown in bold, red: ATC, aspartate transcarbamylase; DHO, dihydroorotase; DHODH, dihydroorotate dehydrogenase; HPRT, hypoxanthine-guanine phosphoribosyl transferase (deficiency of this enzyme results in Lesh-Nyhan syndrome); OTC, ornithine transcarbamylase; PNP, purine nucleoside phosphorylase; and UMPS, uridine monophosphate synthase. Intermediates, substrates, or products: ARG, arginine; ASA, argininosuccinic acid; ASP; aspartic acid; CIT, citrulline; CP, carbamyl phosphate; GLN, glutamine; GMP; guanosine 5'-monophosphate, IMP; inosine 5'-monophosphate; ORN, ornithine; $P_{\mathrm{i}}$, pyrophosphate; and PRPP, phosphoribosyl pyrophosphate.

amino acids (including eight of nine essential amino acids) were moderately to significantly below their respective reference intervals; plasma arginine and citrulline were markedly low at $5 \mu \mathrm{M}(\mathrm{RI} 40-160 \mu \mathrm{M})$ and $<4 \mu \mathrm{M}$ (RI $10-60$ $\mu \mathrm{M})$, respectively. Plasma and urine free and total carnitine and multiple acylcarnitines were markedly above their respective intervals, but were not diagnostic for a specific metabolic disorder; urine total and free carnitine were 5,029.07 $\mu \mathrm{mol} / \mathrm{g}$ creatinine (RI 62.74 - $368.19 \mu \mathrm{mol} / \mathrm{g}$ creatinine) and 2,714.72 $\mu \mathrm{mol} / \mathrm{g}$ creatinine (RI $7.87-237.34 \mu \mathrm{mol} / \mathrm{g}$ creatinine), respectively. Interestingly, elevated levels of OA (43 $\mu \mathrm{g} / \mathrm{mg}$ creatinine; $\mathrm{RI} \leq 5 \mu \mathrm{g} / \mathrm{mg}$ creatinine), citramalic (14 $\mu \mathrm{g} / \mathrm{mg}$ creatinine; RI $\leq 5 \mu \mathrm{g} / \mathrm{mg}$ creatinine) and other compounds suggestive of physiologic stress (3-hydroxybutyric, acetoacetic, lactic, and pyruvic acids) were noted by urine organic acid analysis. Spot urinary uric acid was $40 \mathrm{mg} / \mathrm{dL}$ with uric acid/creatinine ratio $1,905 \mathrm{mg} / \mathrm{g}$ creatinine. Molecular testing for OTC deficiency by sequencing and deletion/ duplication analysis of the OTC gene was negative.

She underwent surgical decompression of her abdomen and a perforated rectum was addressed. Over the following 9 days, she was weaned from vasoactive support and liberated from the ventilator. The local Child Protection Team diagnosed her with inflicted trauma, partial to full thickness burns on lower extremities and concern for sexual abuse. Neurologic function was grossly normal at hospital discharge. Ammonia, urine organic acids, urine and plasma acylcarnitine profiles, and plasma amino acids all normalized after recovery. Spot urinary uric acid after recovery was 27 $\mathrm{mg} / \mathrm{dL}$ with uric acid/creatinine ratio $1,038 \mathrm{mg} / \mathrm{g}$ creatinine. 
Table 1. Differential Diagnosis for Urinary Orotic Acid Excretion

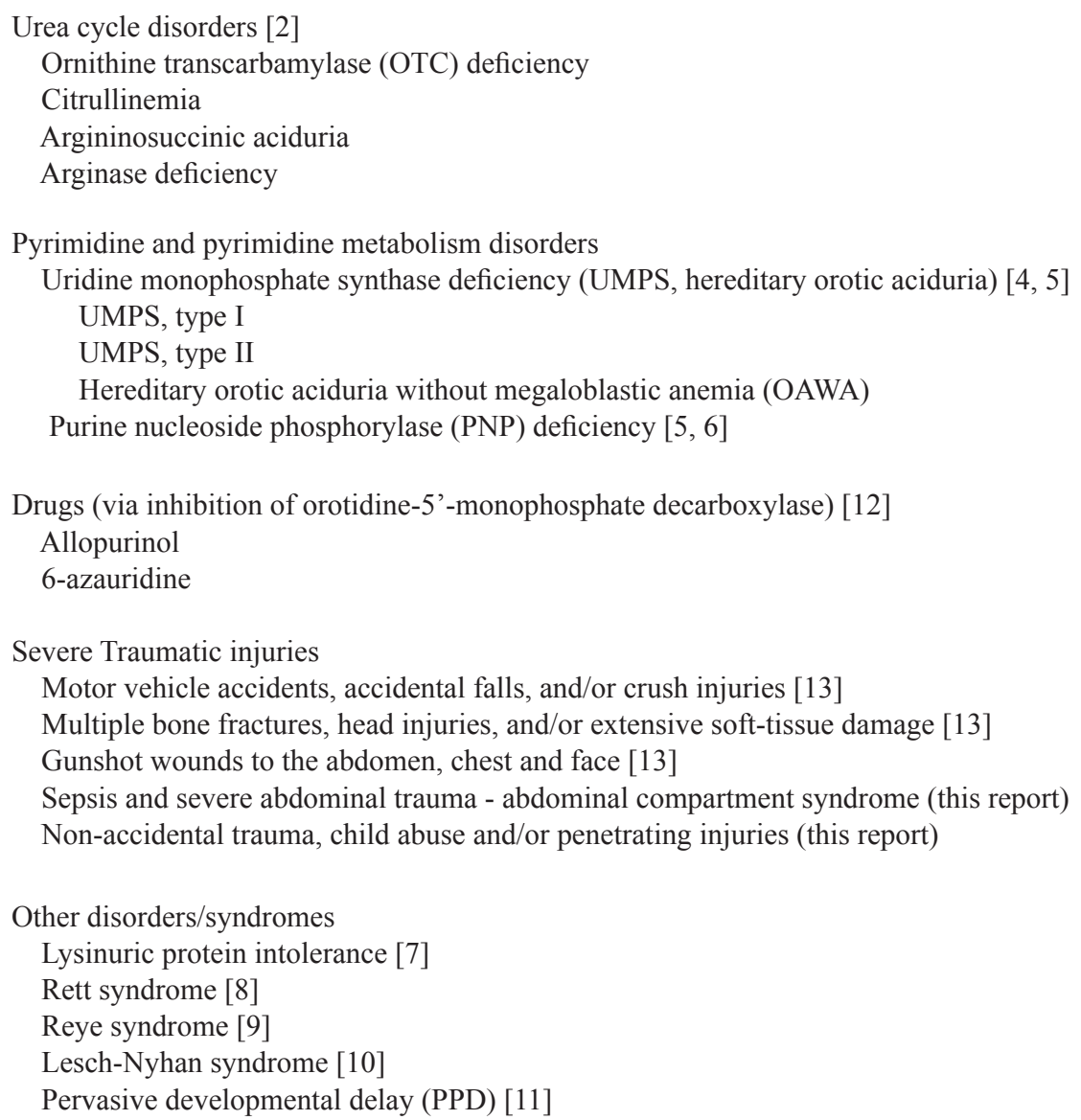

\section{Discussion}

Hypermetabolic responses with respect to pyrimidine, purine and polyamine metabolisms with concomitant orotic aciduria have been reported in adult trauma victims during the early catabolic phase of injury [13]. Decreased intracellular concentrations of phosphoribosyl pyrophosphate (PRPP) in lymphoblasts have been associated with increased accumulation of OA [14]. PRPP deficiency may arise from increased utilization of PRPP by phosphoribosyl transferases, such as hypoxanthine-guanine phosphoribosyl transferase (Fig. 1), in response to increased nucleotide catabolism (or reutilization) during early catabolic phases of severe trauma injuries. Such catabolic states could then result in PRPP becoming limiting for uridine monophosphate synthase (Fig. 1) resulting in accumulation of $\mathrm{OA}$ and consequently increased orotic aciduria.

The diagnostic utility of orotic aciduria in IEMs is well known. A urea cycle disorder may be high on the differential in an individual presenting with hyperammonemia, altered mental status and elevated urinary OA, often leading to fur- ther biochemical and molecular testing. This case is significant for it highlights the association of transiently elevated urinary orotic acid and mild uricosuria with severe trauma in children. Further study is warranted to determine if $\mathrm{OA}$ excretion could be used clinically as a biomarker of the catabolic state of pediatric trauma or other critical illness.

\section{Acknowledgement}

We thank Dr. Douglas S Kerr for critically reading this manuscript.

\section{References}

1. Saudubray JM, Van den Berghe G, Walter J. Inborn metabolic diseases: diagnosis and treatment. 5th ed. Berlin: Springer, 2012.

2. Brosnan ME, Brosnan JT. Orotic acid excretion and arginine metabolism. J Nutr. 2007;137(6 Suppl 2):1656S- 
$1661 \mathrm{~S}$.

3. Summar ML, Koelker S, Freedenberg D, Le Mons C, Haberle J, Lee HS, Kirmse B. The incidence of urea cycle disorders. Mol Genet Metab. 2013;110(1-2):179-180.

4. Bailey CJ. Orotic aciduria and uridine monophosphate synthase: a reappraisal. J Inherit Metab Dis. 2009;32(Suppl 1):S227-233.

5. Boss GR, Seegmiller JE. Genetic defects in human purine and pyrimidine metabolism. Annu Rev Genet. 1982;16:297-328.

6. Cohen A, Staal GE, Ammann AJ, Martin DW, Jr. Orotic aciduria in two unrelated patients with inherited deficiencies of purine nucleoside phosphorylase. J Clin Invest. 1977;60(2):491-494.

7. Rajantie J. Orotic aciduria in lysinuric protein intolerance: dependence on the urea cycle intermediates. Pediatr Res. 1981;15(2):115-119.

8. Thomas S, Oberholzer V, Wilson J, Hjelm M. The urea cycle in the Rett syndrome. Brain Dev. 1990;12(1):9396.
9. Chatterjea MN, Shinde R. Textbook of medical biochemistry. 8th ed. New Delhi: Jaypee Brothers Medical Publications (P) Ltd., 2012.

10. Hoffmann GF, Zschocke J, Nyhan WL. Inherited metabolic diseases: a clinical approach. Heidelberg: Springer, 2010.

11. Abdul-Rahman OA, Hudgins L. The diagnostic utility of a genetics evaluation in children with pervasive developmental disorders. Genet Med. 2006;8(1):50-54.

12. Salerno C, Crifo C. Diagnostic value of urinary orotic acid levels: applicable separation methods. J Chromatogr B Analyt Technol Biomed Life Sci. 2002;781(12):57-71.

13. Jeevanandam M, Hsu YC, Ramias L, Schiller WR. Mild orotic aciduria and uricosuria in severe trauma victims. Am J Clin Nutr. 1991;53(5):1242-1248.

14. Parker NF, Jack I, Van Der Weyden MB. Adenosine- and deoxyadenosine-mediated altered pyrimidine metabolism in human adeosine deaminase-deficient lymphoblasts. J Lab Clin Med. 1982;99(5):731-739. 